\title{
Ethiopian jawbone may mark dawn of humankind
}

\section{A 2.8-million-year-old mandible and a digital model of a key fossil paint a complicated picture of the genus Homo.}

\section{Ewen Callaway}

04 March 2015

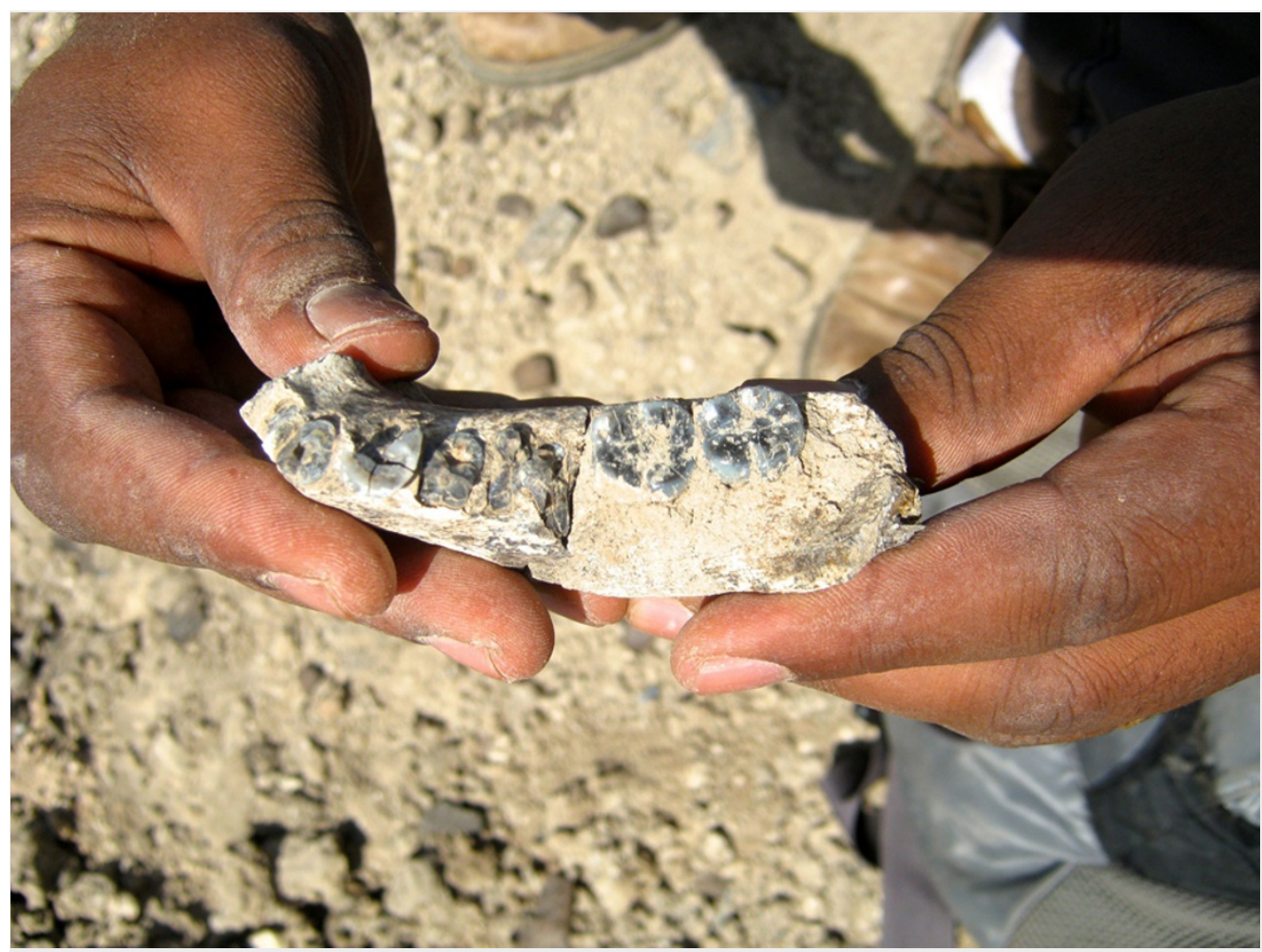

Kaye Reed

The 2.8-million-year-old jawbone that may have come from the first Homo.

A 2.8-million-year-old battered jawbone from Ethiopia may represent the earliest ancient human fossil ever discovered — pushing back the known origins of humankind by 500,000 years. The remains, alongside a digital reconstruction of a damaged fossil from a key early-human species, point to an evolutionary explosion at the dawn of our genus, Homo.

Modern humans, Homo sapiens, are the latest link in a chain of ancestry that stretches back 5 to 7 million years to a common ancestor with chimpanzees and bonobos, humanity's two closest living relatives. An incomplete fossil record means that researchers have had a hard time finding the other links of that chain, and distinguishing true human ancestors from evolutionary dead-ends - side branches in the family tree.

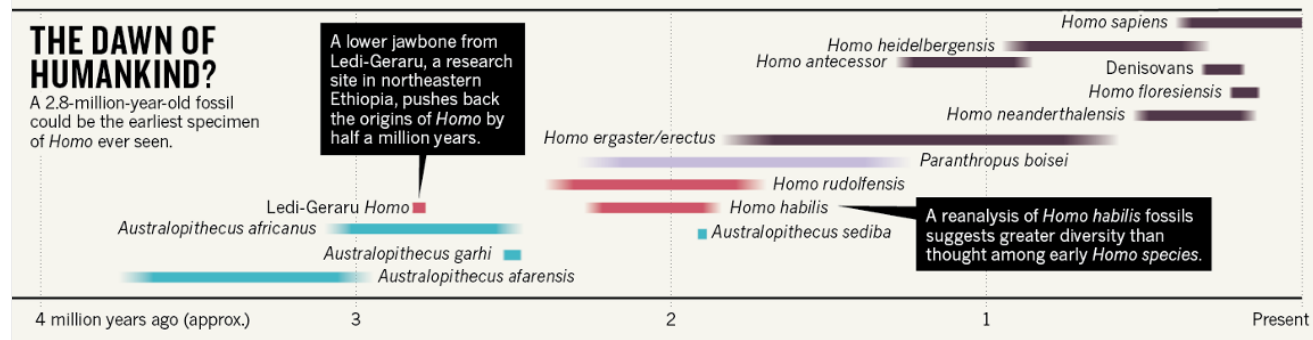

Homo erectus is one ancestor, most agree. The species emerged in East Africa around 2 million years ago. Its big brain and tall body are all similar to those of modern humans. Another possible link is a more ape-like creature that lived around 3 million to 4 million years ago: Australopithecus afarensis, which walked upright but stood only just over a metre tall and had a puny brain. One species that may bridge the gap between these two is Homo habilis, but some researchers speculate that at least two 'early Homo' species existed between 3 million and 2 million years ago. 


\section{The first ancient human?}

On 29 January 2013, scientists combing a stretch of northeastern Ethiopia's Afar region found a 2.8-million-year-old jawbone that may belong to the earliest of the Homo species - perhaps the first ancient human. Its teeth are small, like those of other Homo species, and the parabolic shape of the jaw is a better match to Homo than to Australopithecus, says Brian Villmoare, a palaeoanthropologist at the University of Nevada Las Vegas. His team reports the discovery in Science ${ }^{1}$. The researchers stopped short of putting a species name to the jaw - until they discover more remains. "We have every intention of finding them, but that's just down to luck," says Villmoare.

"I think they make a good case that it's the sort of creature that, if it wasn't the earliest evidence of Homo, was certainly somewhere close to it ," says Bernard Wood, an anthropologist at George Washington University in Washington DC. "It looks Homo-ish to me, but l'd like to see their numbers," agrees Daniel Lieberman, a palaeoanthropologist at Harvard University in Cambridge, Massachusetts, referring to precise measurements of the jaw.

In another paper, members of Villmoare's team suggest that around 2.8 million years ago, climate change transformed forests in the Afar region into grasslands ${ }^{2}$. "There are two ways to handle that: one is to go extinct, the other is to make some sort of evolutionary adaptation," says Villmoare. Homo sapiens' ancestors, he speculates, turned to hunting game, eventually developing larger brains and more agile bodies.

\section{A messy history}

But Homo's origins are increasingly confusing, as a reanalysis of 1.8-million-year-old fossil specimens, reported in Nature ${ }^{3}$, demonstrates. In the early 1960s, a team led by palaeoanthropologists Louis and Mary Leakey found a deformed lower jaw, hand and partial skull in Olduvai Gorge, Tanzania.

"It was reported in a very informal way in Nature4: 'Sir: I found a bone and I'm showing you a picture now. Goodbye,"” says Fred Spoor, a palaeoanthropologist at University College London. The Leakey team later designated the remains as a new species that they called Homo habilis, meaning the handy man ${ }^{5}$. They contended that members of the species had made stone tools that had been discovered nearby years earlier.

But the material was so sparse that all manner of other fossils were later designated $H$. habilis.

"It's how I cut my teeth as a palaeoanthropologist — working with the mess that is Homo habilis," says Lieberman. "It became very clear that there was too much variation to accommodate just one species."

To help to clean up the mess, Spoor's team went back to the Leakeys' original $H$. habilis fossils and determined the true shape of the jawbone. The researchers made a three-dimensional model of the mandible using a computed tomography (CT) scanner, and found that the deformation of the bone was caused by lots of small breaks.

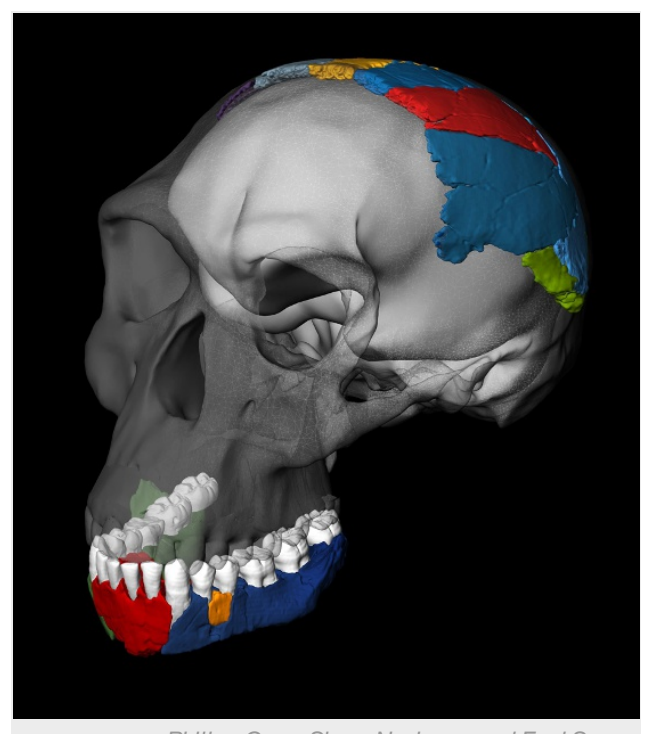

Philipp Gunz, Simon Neubauer and Fred Spoor

The reconstructed Homo habilis skull based on bones from Olduvai Gorge, Tanzania.
Reconstructing the broken pieces revealed that the jaw was more primitive-looking than the team expected. It was long and thin, and the rows of teeth on opposite sides were nearly parallel — more like an Australopithecus's jaw than a human's rounder one. A reconstruction of the skull bones, however, revealed that the brain was larger than expected, similar in size to that of $H$. erectus.

Previously discovered upper-jaw fossils classed as $H$. habilis, and dating back as far as 2.3 million years ago, look too different from the newly reconstructed jaw to belong to the same species, says Spoor's team. This suggests that the species that predated $H$. erectus were a diverse bunch..

The two reports confirm that 'early Homo' species showed lots of variation, yet none stands out as an obvious ancestor of $H$. erectus, says Lieberman. "The question on everybody's mind is what happened at this transition to the origin of early Homo and in early Homo," he says. "We just don't understand what's going on." 


\section{References}

1. Villmoare, B. et al. Science http://dx.doi.org/10.1126/science.aaa1343 (2015).

2. DiMaggio, E. N. et al. Science http://dx.doi.org/10.1126/science.aaa1415 (2015).

3. Spoor, F. et al. Nature 519, 83-86 (2015).

4. Leakey, L. Nature 189, 649-650 (1961).

5. Leakey, L. S. B., Tobias, P. V. \& Napier, J. R. Nature 202, 7-9 (1964)

Pierre-Francois PUECH • 2015-03-05 09:58 AM

That the Homo habilis O.H.7 jaw was more primitive-looking than expected, with the rows of teeth on opposite sides nearly parallel - more like an Australopithecus's jaw, has been evidenced with the analyses of the extreme variation in morphology and size in Australopithecus afarensis :Hadar, Laetoli and Garusi hominids. The Garusi hominid has to say about the evolution leading to rows of teeth nearly parallel with some human characteristics still present on the first recovered jaw from Dmanisi. Dmanisi 1, unearthed in 1991, showed to us that the face of the European was settled forward and the jaws, long and narrow, similar to those of Homo habilis O.H. 7 known on the African continent. https://archive.org/details/WhenManBeganOrTheDoorstepOfHominityMillionYearsAgoAtGarusi 